\title{
THE ELECTROENCEPHALOGRAM IN CONGENITAL HYPOTHYROIDISM: A STUDY OF 10 CASES
}

\author{
BY
}

\author{
ERIC A. NIEMAN*
}

\author{
From Royal Southern Hospital, Liverpool
}

Cretinism in childhood, like myxoedema in adults, is a condition which is due to lack of circulating thyroid hormone, and for which there is specific hormone replacement therapy. It is a natural assumption that, provided therapy is begun early and continued in optimum dosage and without interruption, the results should be good. Unfortunately, although satisfying improvements in somatic development take place, the child's mental development is often unsatisfactory and difficult to predict.

In 1910, Siegert reported severe mental retardation in some cretins despite prolonged treatment. In 1929, Tredgold reported a number of cretins who obtained no mental improvement with thyroid. Bruch and McCune (1944) could find only three cretins with normal intelligence in a group of 23 treated cases. Other authors (Lucas, 1927; Gesell, Amatruda, and Culotta, 1936; Goodkind and Higgins, 1941; Wagner, 1943) agree that there is a poor relationship between therapy and mental prognosis.

Numerous reasons have been invoked to explain this discrepancy. Tredgold (1929) postulated two types of cretins: in the first the arrested development is due to lack of thyroid and the child is capable of normal mental and somatic development with thyroid replacement; in the second there is an associated primary amentia which cannot respond to thyroid although physical development is accelerated.

In 1885, Hadden reported cortical atrophy in the brains of two cretins, and Lotmar (1929) reported histological changes in the brain cells of cretins at necropsy, and concluded that when deficiency of thyroid occurs in foetal life it causes disturbances in the development of the brain.

The advent of electroencephalography provided an index of cerebral activity in the living patient. Kreezer (1937) studied the electroencephalograms of a few cretins (in a group of mental defectives,

* Present address: St. Mary's Hospital, Paddington, London. mongols, etc.) and reported a "relatively low fre- 듬 quency of alpha waves". Isolated cases of cretinism $\frac{\bar{\omega}}{\vec{D}}$ have also been studied by Jung (1950), who noted $\stackrel{\varnothing}{\Omega}$ excessive slow activity, and by Schütz and Müller (1953).

The first report of electroencephalographic studies in a larger series of cases was by D'Avignon and $\overrightarrow{\vec{\omega}}$ Melin (1949). They studied 22 patients: eight with normal E.E.G.s, five with slight abnormalities, seven with markedly abnormal E.E.G.s, and two with unusually rapid activity for their ages. They remark that the E.E.G. in treated cases of congenitat $-\vec{c}$ hypothyroidism seems to indicate that in cases wi a low I.Q. (60 and under) the E.E.G. is marked, 을 immature even when these patients had receivent. adequate thyroid treatment and had shown normâ somatic development. On the other hand, almostt all psychically normal patients (I.Q. above 90) shog d a normal alpha rhythm.

Topper (1951) took E.E.G.s of seven cretins wisio had remained feeble-minded despite adequate treat-o ment and of six cretins who were normal mentally. All the latter had normal E.E.G.s Of the seven feeble-minded cretins, five showed "diffuse cerebral dysfunction." She thought that

"E.E.G. studies in infancy can be of prognostic import, since no amount of thyroid can bring about normal mentality in the presence of cerebral dys-o function, whereas if the E.E.G. shows a normally functioning brain, adequately pursued therapy can bring about normal mentality in congenital hypothyroidism."

Mai and Schaper (1953) found in their series seven patients with normal E.E.G.s after adequateo thyroid therapy, and this correlated well with their physical and mental improvement. Thirteen patients, however, remained mentally retarded (some had been treated inadequately or sporadically): of these, 12 had abnormal records, for the most part, low voltage, poorly represented alpha activity, ance excessive theta activity.

Chaptal, Passouant, Jean, Cadilhac, and Carl $\tilde{\rho}$ (1956) describe nine cases of "myxoedeme pure" 
due to thyroid agenesis, and eight cases of "myxoedeme encephalopathique" (in which there is associated brain damage, proved in most cases by pneumoencephalography), which showed some degree of cortical atrophy and hydrocephalus. (It is interesting to note that earlier workers, including Mai and Schaper, 1953, had been unable to demonstrate any abnormality in this type of case on pneumoencephalography.) Chaptal et al. state that abnormalities of the E.E.G. in congenital myxoedema of childhood vary greatly according to the type of hypothyroidism, whether primary (thyroid agenesis) or secondary to an encephalopathy. In the former case the cerebral disorder is manifested by a delay in maturation of cerebral electrical activity. In the latter case there are often major signs of cerebral dysfunction with localized irritative abnormalities such as those encountered in cerebral atrophy in children (often high-voltage delta waves and spikes).

It appears, then, that previous workers agree that there are changes in the E.E.G. in many cases of untreated hypothyroidism in childhood, though there is no distinctive pattern of change. Increased theta activity and low voltage have been most commonly suggested as indices of lack of thyroid secretion. Most of the cases reported have been of E.E.G. changes in treated cretins, or of untreated cretins in later childhood and adult life. There are no detailed reports of the E.E.G. picture in infant cretins. The first three cases described in this paper were all diagnosed, and the E.E.G.s obtained, under the age of 6 months. They show in the waking state an unusually regular theta activity of remarkably constant amplitude and frequency, little artefact, and a noticeably small amount of delta activity. These records might be regarded as unusually mature for the child's age, though mental development in each case was delayed. Low voltage is a feature of two of these records only, and I would suggest, as in adult hypothyroidism (Nieman, 1958), that the mental torpor renders prominent and regular the dominant rhythm. The absence of dysrhythmia, paroxysmal activity, or spikes indicates probably a good mental prognosis if therapy is adequate. Cerebral development in utero (under the influence of maternal thyroxine) has presumably been normal; the E.E.G. changes at 3 to 6 months of age may be due to the direct effect of reduced cerebral metabolism rather than to retarded cerebral development. Thyroid therapy instituted at this stage should permit of normal mental growth and maturation of the E.E.G.

\section{Case Reports}

Case 1.-J. O'H, a girl, was seen at the age of 3 months. She had a cretinoid appearance, a protuberant abdomen, an umbilical hernia, dry skin, and was constipated. Radioactive iodine studies showed considerable hypofunction of the thyroid and the serum cholesterol was $775 \mathrm{mg} . \%$. The E.E.G. shows the mixture of delta and theta activity that one expects at this age although probably the theta activity is somewhat more prominent than usual for a child of only 12 weeks. It was notable, however, that we obtained a complete record almost entirely free from artefact, the baby being unusually quiet. The dominant frequency was a 4 per sec. theta rhythm with an amplitude of 20 microvolts.

Unfortunately, she contracted a severe gastro-enteritis, due to E. Coli 0111 , a few days later, developed bronchopneumonia and died. At necropsy she was found to have a very tiny thyroid, the picture being one of agenesis of the thyroid, and not a colloid type of gland. There was no abnormality in the brain.

Case 2.-S.F.G., a girl, was also diagnosed as a cretin at the age of 3 months. A full-term normal delivery, she had never really thrived from birth. Radioactive iodine studies showed a maximum uptake of less than $2 \%$, and the serum cholesterol was $90 \mathrm{mg} . \%$. Radiographs of the spine showed a slight "slipper deformity" of L.2. The bone age was normal. The E.E.G. showed little artefact; on the whole a rather flat trace with short bursts of $2 \frac{1}{2} \mathrm{c} / \mathrm{s}$ delta activity with an amplitude of 35 microvolts. With thyroid extract she has been making excellent progress to date; unfortunately, I have not been able to obtain a repeat E.E.G.

Case 3.-C.F., a girl, aged 5 months, was delivered normally at full term. She appeared to develop normally until the age of 4 months, when it was noticed that she was having only one motion per week. Her face was puffy, her hair fine and smooth, and her feet were very cold (in June). The tongue was protuberant and she had a pot belly with an umbilical hernia. Her head control was not good though she could sit with assistance. She held toys but she did not pass them from one hand to another. She seemed interested in her surroundings.

An E.C.G. was of low voltage, with isoelectric T waves. A radiograph of the spine showed slight "slipper deformity" of the body of L.1 and slight central "beaking" of the body of L.2. The serum cholesterol level was $182 \mathrm{mg} . \%$.

Assessment by a clinical psychologist suggested a developmental age of 20 weeks compared with a chronological age of 25 weeks. The E.E.G. (Fig. 1) shows a remarkably regular and stable $4 \mathrm{c} / \mathrm{s}$ rhythm in all leads with an amplitude of up to 100 microvolts. When the E.E.G. was repeated (Fig. 1a) she had been having thyroid, grain $\frac{1}{2}$, daily for four months and was aged 10 months. She was doing well though she was still recognizable as a cretin. She was alert, warm, friendly, and interested in her surroundings. She held her head well and was sitting. She was having one, sometimes two, motions a day. The E.E.G. is now much less regular. The dominant rhythm has speeded up to 5 c.p.s. ( 75 microvolts) and there are some more rapid waves. A third record at the age of 1 year showed no further change. 
This stability of the theta rhythm is seen not only in infancy but at other ages in untreated cretinism. The next case illustrates this regularity in a child of
3 years and 8 months, in whom thyroid therapy produced a rapid change in the E.E.G., and is developing normally in spite of late diagnosis.
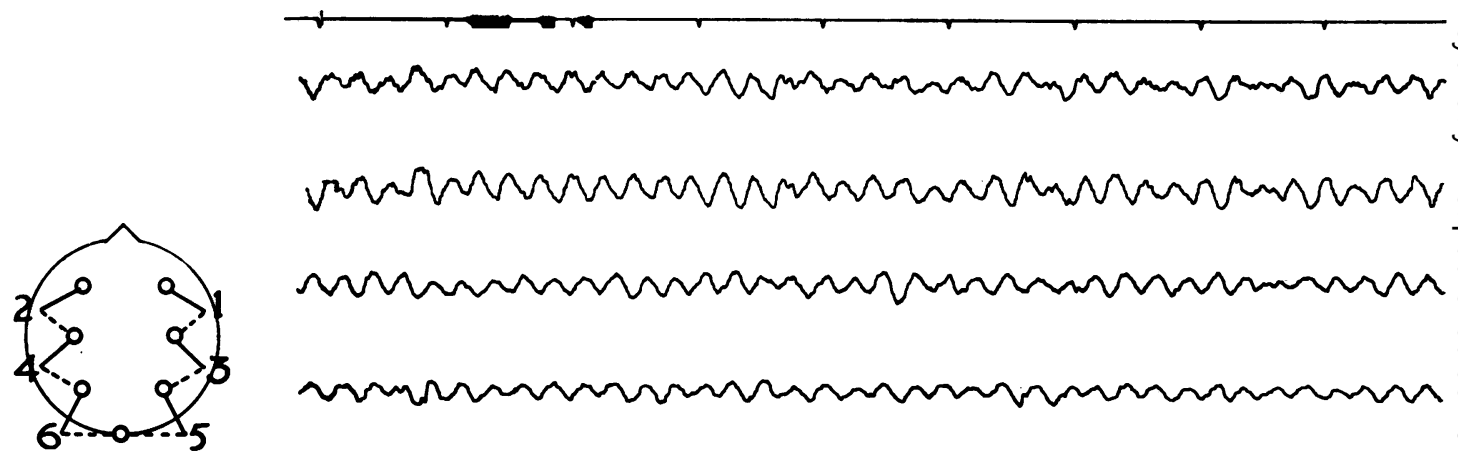

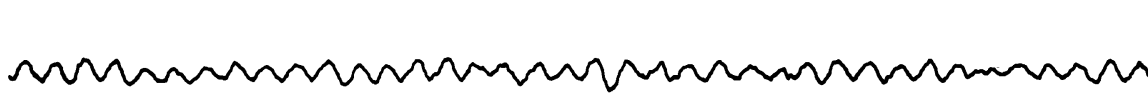

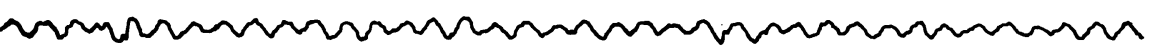

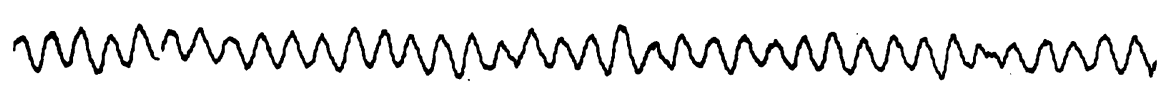

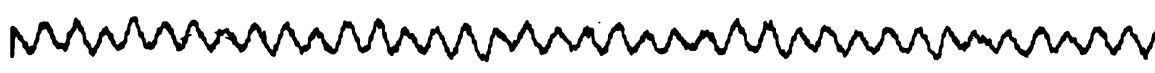

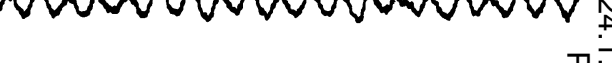
1 see Jloopl

FIG. 1.-Untreated cretin aged 5 months. A regular, synchronous and symmetrical $4-4 \frac{1}{2} \mathrm{c} / \mathrm{s}$ theta rhythm.
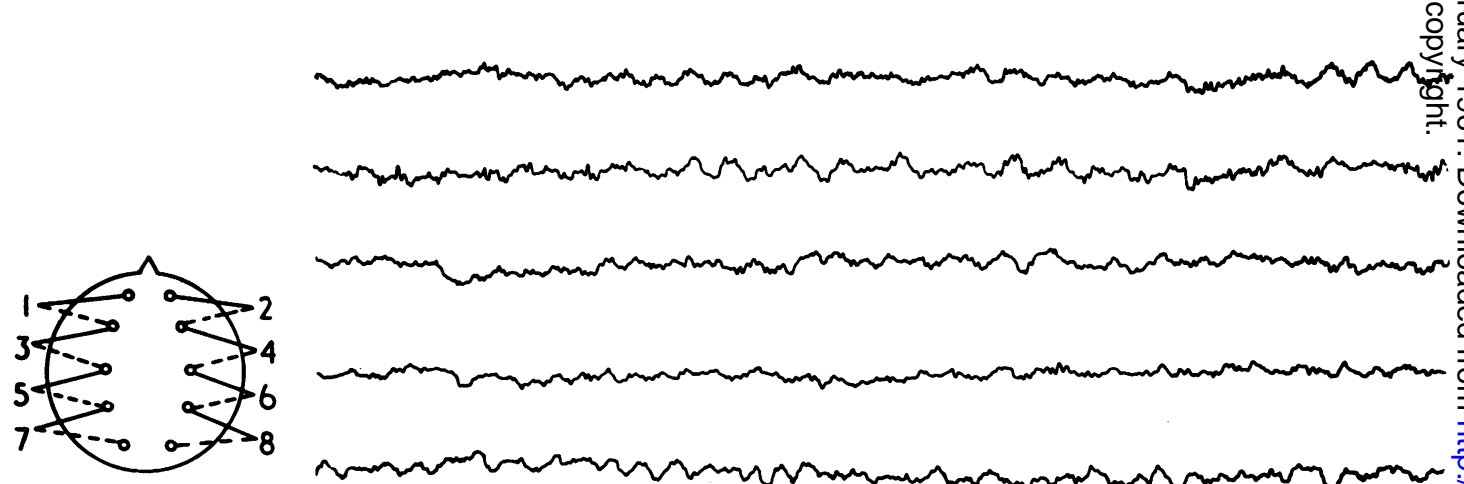

$\overbrace{}^{2}$

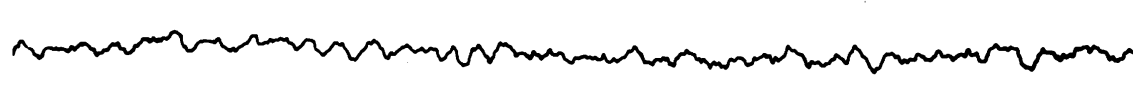

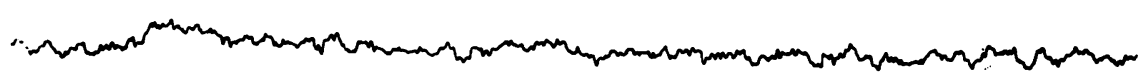

(2)

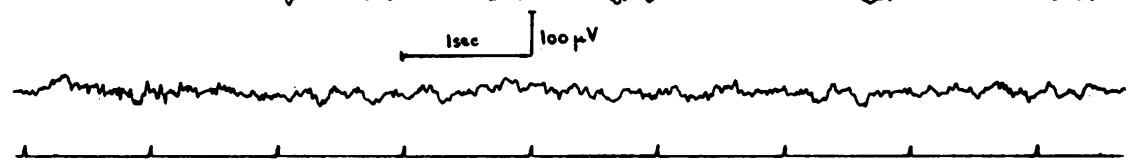

FIG. 1a.-Record after four months' treatment with thyroid, grain $\frac{1}{2}$ daily. More irregular 5-6 c/s rhythm with some fast activity. 
Case 4.-L.K., a girl, aged 3 years and 8 months, sat up at 8 months. Teething began at 6 months but the teeth were carious. She began to walk at 2 years. At the age of diagnosis she could say simple words only, could not dress herself, was incontinent of urine, but could feed herself with a cup and spoon. Her bowels opened twice a week. She was pale and puffy-eyed, with a dry skin, and looked like a cretin. Her bone age was 6 months. The E.E.G. shows a regular mixture of $3 \frac{1}{2}$ and 4 c.p.s. activity with an amplitude up to 75 microvolts. A repeat E.E.G. after only five weeks' treatment with L-thyroxine sodium, $0.1 \mathrm{mg}$. daily, shows considerable change. There is now a dominant 8-9 c/s occipital alpha rhythm as well as theta, and a very little low amplitude delta activity. This child now, at the age of 7 years, is normal for her age in weight and height, goes to school, and is said by the school teacher to be average for her age in class. She is having $0.25 \mathrm{mg}$. of thyroxin daily.

Case 5.-A.M.R., a boy aged 8, had a similar type of record, immature with a stable theta rhythm. He was diagnosed in infancy as a cretin, but was treated sporadically and inadequately with intermittent thyroid, grain 1 daily. He was slow at school, lacked concentration, was constipated, and below average height for his age. The record shows a fairly regular theta rhythm of $5-7 \mathrm{c} / \mathrm{s}$ with occasional bursts of higher voltage of $4 \mathrm{c} / \mathrm{s}$ theta rhythm (up to 75 microvolts). He has improved considerably since thyroid dosage was increased and given regularly, and is in the correct class for his age at school (though near the bottom of that class). A further E.E.G. has not been obtained.
Delay in diagnosis, however, although it does not preclude improvement both somatic and psychic on treatment, may yet determine a failure of the child to keep pace with its fellows. Progress may be steady and continuous but may fail to make up the ground that has been lost, as in the next case.

Case 6.-A.M., a girl, diagnosed as hypothyroid in June, 1954, at the age of 5 , has a twin sister (heterozygous) who is normal (F.M.). Angela (the cretin) had been noticed to be much slower than her sister Felicity, and although heavier, was about 2 in. less in height. She walked at 18 months, was continent by 20 months, but at the age of 5 was still slow in speaking, lethargic and placid. Her hair was coarse, her voice deeper than her sister's, and her abdomen prominent. The bone age was 1 year, and the serum cholesterol $350 \mathrm{mg} . \%$.

The E.E.G. (Fig. 2) of A.M. (cretin aged 5) shows a mixture of delta and 4-5 c/s theta activity. There is little visible alpha rhythm. The E.E.G. of F.M., the normal twin aged 5 (Fig. 2a), shows, in contrast, an $8 \mathrm{c} / \mathrm{s}$ alpha rhythm with only a little low amplitude theta rhythm anteriorly.

The records of the two girls were repeated three years later when they were 8 years old. Angela appeared mentally alert, spoke normally, and, by herself, would not have been recognizable as a cretin. But she is two classes below her sister in school, and is still plumper and slightly shorter ( $1 \frac{1}{2}$ in.) than her sister. Har progress, in other words, has been good, but still lags behind her twin sister. It will be seen that the E.E.G. traces remain very different. The record of Angela (Fig. 2b) shows still an
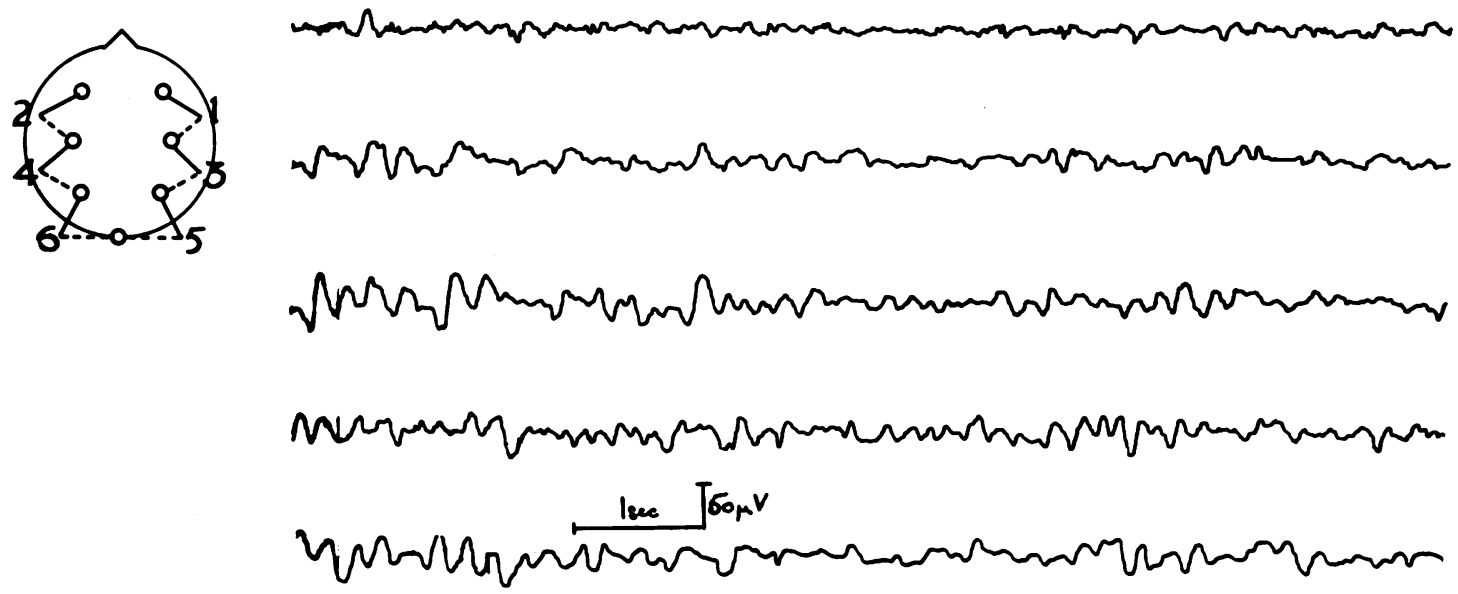

FIG. 2.-Untreated cretin (A.M.) aged 5. Mixture of delta and theta rhythms. 


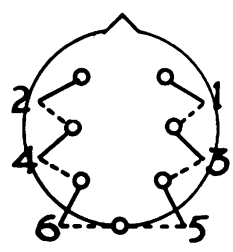

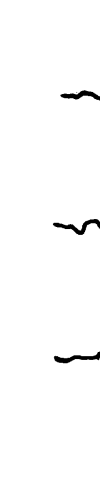

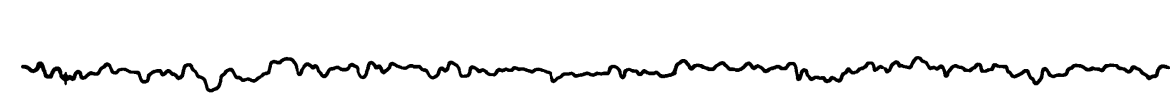

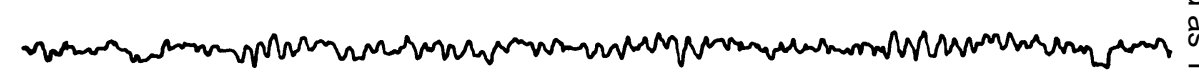

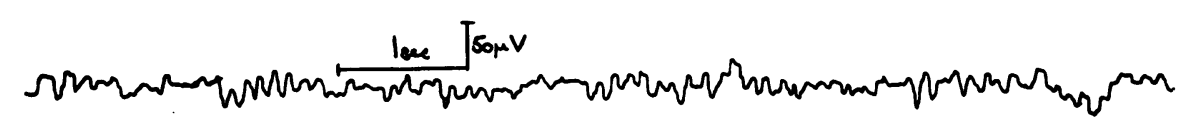

Fig. 2a.-Patient's twin sister (F.M.) at same age. Well formed $8 \mathrm{c} / \mathrm{s}$ alpha rhythm.

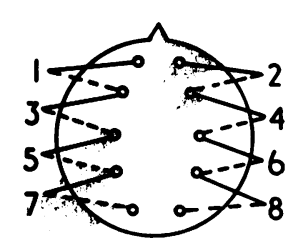

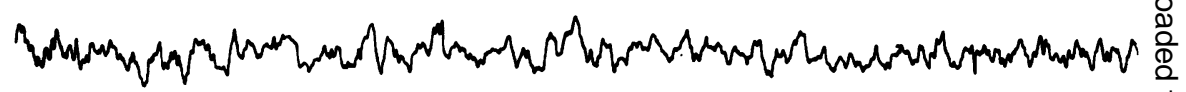

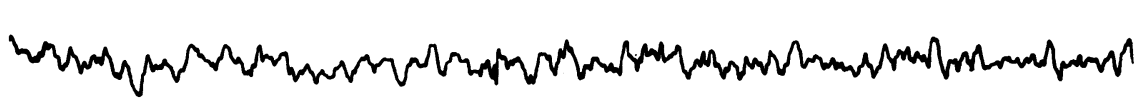

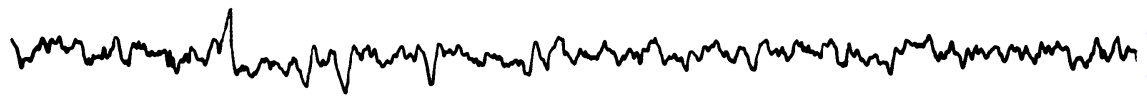

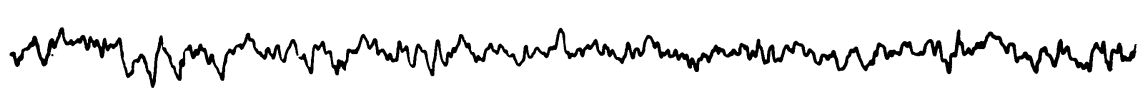
WWM

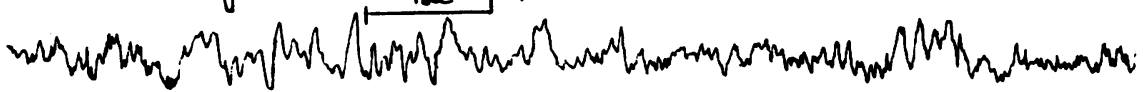

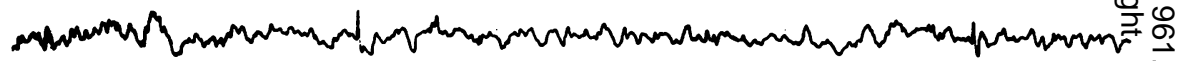

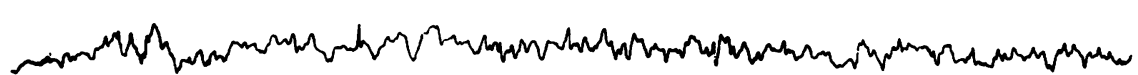

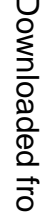




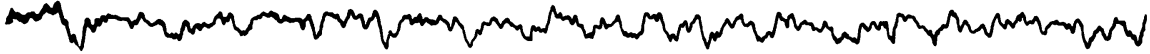

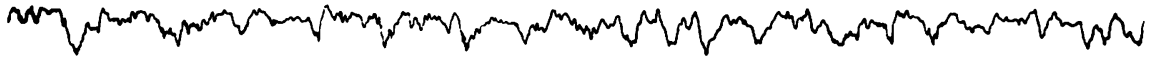
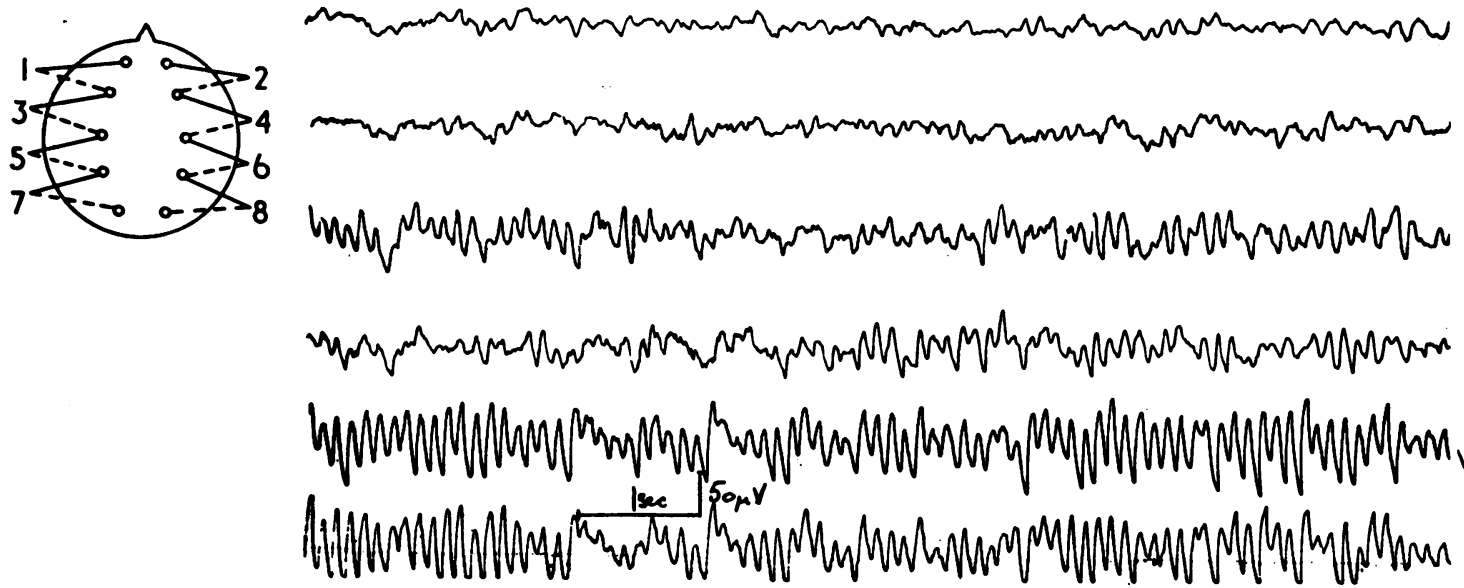

FIG. 2c.-F.M., aged 8. Well developed 9-10 c/s alpha rhythm and little slow activity.

irregular mixture of delta and theta activity with only a very small amount of $8 \mathrm{c} / \mathrm{s}$ alpha rhythm, whilst that of Felicity, her twin, now shows a well-developed 9-10 c/s occipital rhythm and only a little slow activity anteriorly (Fig. 2c). In the case of Angela, one would give a very guarded prognosis of ultimate mental attainment.

The next two cases are of children in whom mental progress has been less fortunate and there is definite evidence of retardation. In one of the two patients fits have occurred.

Case 7.-V.W., a girl, was a post-mature baby, delivered by Caesarian section, who was diagnosed as a cretin at the age of 5 months, and began to receive thyroid at that age. Her physical progress was good, but mentally her progress was very slow. An E.E.G. was first obtained at the age of 2 years and 2 months. She could not stand, said only a few single words, and, although having thyroid grain $2 \frac{3}{4}$ daily, was still somewhat dull and lethargic.

The E.E.G. showed a poorly-developed occipital trace consisting largely of theta waves, with a little delta activity. In addition, throughout the record there was constant rapid activity with irregular spikes in the frontal leads, especially on the right. At the age of 4, although some mental improvement had occurred, she was still obviously retarded in that speech development was poor. Physically, she was normal, in fact above average height for her age. The E.E.G. shows that while there is now a good deal of alpha activity posteriorly, the frontal rapid activity remains.

Case 8.-R.G., a boy, was started on thyroid at 3 months and it was given regularly until 20 months, when his mother discontinued it as she thought it was not doing any good. However, given in higher dosage, he improved again. The first E.E.G. was performed at the age of 4 years. At this time his somatic development was satisfactory, and he was active and alert. The E.E.G. showed a dominant $7 \frac{1}{2} \mathrm{c} / \mathrm{s}$ rhythm, with some slower activity throughout the theta range. It might be regarded as a normal record for a child of this age.

At the age of 5, he had a major fit, which lasted 15 minutes. (At this time he was taking thyroid grains 5 , daily.) Two weeks later an E.E.G. was obtained. Although this record is perhaps not grossly abnormal for a boy of 5 , it shows no improvement compared with the previous record of a year ago, and there is more slow activity present, with a tendency for the $4 \mathrm{c} / \mathrm{s}$ theta activity to occur in short bursts. This boy's progress has continued to lag behind normal, and now, at the age of 8 , he is still very obviously retarded, is enuretic, and has had one more fit.

Case 9.-E.J.S., a boy, aged 9, presented as a case of dwarfism due to masked hypothyroidism (see BlochMichel, Tubiana, and Brizard, 1957). His school progress was said to be satisfactory, but he was not as active as the other children, was constipated, and had frequent bronchitis. His height was 41 in. and his 

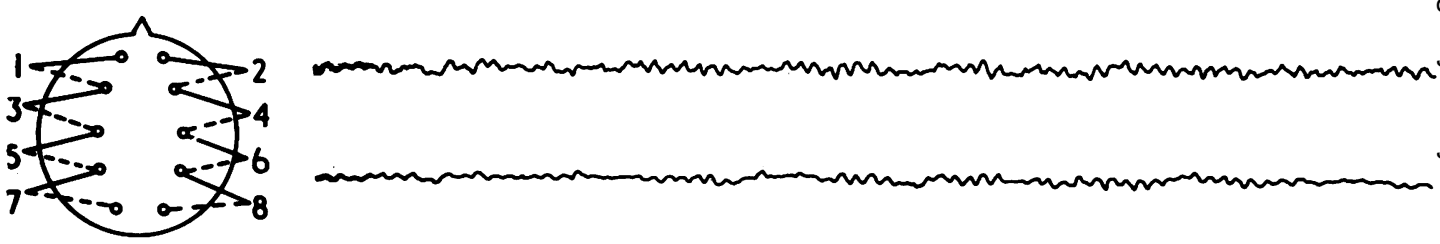

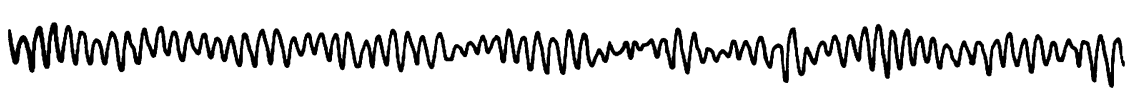

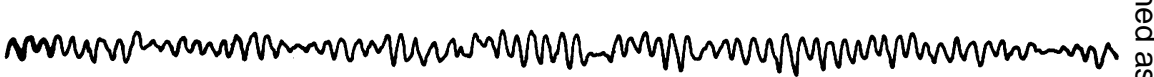

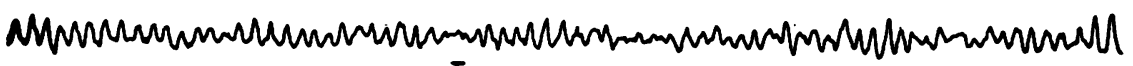

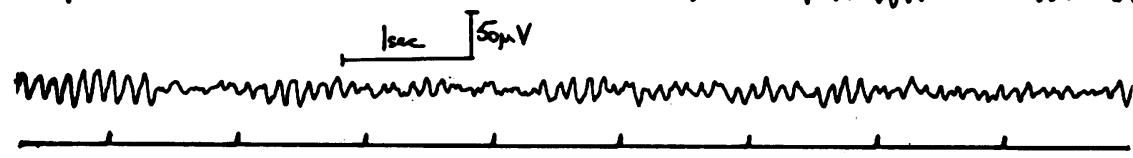

Fig. 3.-Cretin aged 33 (no thyroid treatment for 10 years). Normal $9 \mathrm{c} / \mathrm{s}$ alpha rhythm.

weight $44 \mathrm{lb}$. His skin was pale, but there were no cretinoid characteristics.

An E.C.G. was of low voltage. Haemoglobin was $76 \%$, showing orthochromic anaemia. Trypsin was found in the faeces, but no excess fat. Blood calcium, phosphorus, alkaline phosphatase, and urea were normal. Serum cholesterol was $203 \mathrm{mg} . \%$ The Wassermann reaction was negative. Bone age was 3 to 4 years.

The E.E.G. shows a fairly well-developed $8-9 \mathrm{c} / \mathrm{s}$ alpha rhythm, with a good deal of $3-4 \mathrm{c} / \mathrm{s}$ activity tending to occur in generalized bursts, an abnormal record for his age. Treatment with thyroid was begun and produced definite improvement. He now has more energy, is more alert in school, his bowels are regular, and in six months he has gained 2 in. in height. His E.E.G., repeated five weeks after starting thyroid, shows an improved alpha rhythm and less slow activity; there was no paroxysmal activity in the record.

Case 10.-M.C., a woman aged 33, was treated from early infancy with thyroid, with benefit. During adolescence she received thyroid sporadically, stopped it at the age of 23, and when I first saw her, she had received no thyroid for 10 years. She was mentally slow, with slow speech, had a dry coarse skin and hair, and a gruff voice. Her pulse rate was 58 per minute, the reflexes sluggish, and the ankle jerks absent. Her height was 54 in. and her weight 6 st. 4 lb. Her B.M.R. was - $10 \%$ and $-25 \%$. The serum cholesterol was $200 \mathrm{mg} . \%$ and the E.C.G. was of low voltage with flat T waves. Radioactive iodine studies showed virtually no uptake, and the serum protein-bound iodine was $0.042 \%$ per litre.
The E.E.G. (Fig. 3) shows a largely $9 \mathrm{c} / \mathrm{s}$ alp $\frac{\rho}{19} \mathrm{a}-$ rhythm, well-developed and sustained (amplitude 50 T microvolts), with some $8 \mathrm{c} / \mathrm{s}$ alpha rhythm and little $10 \mathrm{c} / \mathrm{s}$ alpha rhythm, a normal record. Tregfment with thyroid, grains 3 daily, has produced remar able clinical improvement. She is more alert, her featushave changed, and she has responded, in fact, as ofles would expect a case of adult myxoedema to respond..Her E.E.G. four months later shows an increase in the dominant frequency of the alpha rhythm to $10 \mathrm{c} / \mathrm{s}$, but, otherwise, no significant change. It appears in this case that treatment in childhood had allowed of normalo development of the E.E.G. and it would seem unlikely음 that there was any associated cerebral agenesis.

\section{Discussion}

One may conclude that in pure hypothyroidism, maturation of the E.E.G. proceeds pari passu with mental development in the adequately treated case, and may become normal. On the other hand, patients:with pronounced mental defect who remain retarded 3 on adequate treatment usually present abnormal $\delta$ records, the likely explanation being an associated 3 cerebral dysgenesis. Topper (1951) considers that 0 the age at which treatment with thyroid is begun may also play a part, and Mai and Schaper (1953) distinguish between athyroidism and hypothyroidism. They consider that in the former, delayed $N$ thyroid therapy may produce irreversible cerebral $N$ changes, whilst in the latter, the presence of minimal N్ 
thyroid secretion may produce the clinical picture of cretinism but prevent an irremediable mental retardation. There is no doubt that in some cases thyroid administration produces dramatic improvement in the E.E.G. (see Case 4) whilst in others (see Case 7) little maturation takes place and abnormalities persist. In further cases, mental improvement and some maturation of the E.E.G. may both take place, yet both lag behind normal (Case 6). There are still many unsolved problems, and larger series of cases are required of cretins diagnosed in infancy and followed carefully throughout childhood.

\section{Summary}

Review of the literature has shown that in treated cretins there is often a discrepancy between physical growth and ultimate mental achievement. This has been attributed to a number of factors, of which a coexisting amentia in a certain proportion of cretins is the most likely. An irreversible post-natal failure of cerebral development due to delay in instituting thyroid therapy may also account for some cases.

It has been shown that electro-encephalography may provide an index of mental progress in these children, and indicate the mental prognosis. Electroencephalographic studies have been made in 10 cretins and the traces correlated with clinical observation. In three children, the initial records were performed under the age of 6 months.

The records in untreated cretins show an unusual stability, regularity, and freedom from artefact, in the waking state. Treatment produces a faster and more irregular record. Paroxysmal activity, spikes, or undue rapid activity suggest associated cerebral dysgenesis and a poor mental prognosis.

I wish to thank Dr. R. R. Hughes for his encouragement and advice. My thanks are also due to Dr. R. W. Brookfield, Professor N. B. Capon, Dr. H. G. Farquhar, Professor J. D. Hay, and Dr. S. E. Keidan for referring patients.

I am grateful to the Research Committee of the United Liverpool Hospitals for providing facilities for this work.

\section{REFERENCES}

Bloch-Michel, H. Tubiana, M., and Brizard, J. (1957). Sem. Hôp. Paris, 33, 454.

Bruch, H., and McCune, D. J. (1944). Amer. J. Dis. Child., 67, 205 Bruch, H., and McCune, D. J. (1944). Amer. J. Dis. Child., 67, 205. (1956). Presse méd., 64, 2257.

D'Avignon, M., and Melin, K. A. (1949). Acta pediatr. (Uppsala), 38, 37.

Gesell, A., Amatruda, C. S., and Culotta, C. S. (1936). Amer. J. Dis. Child., 52, 1117 .

Goodkind, R. P., and Higgins, H. L. (1941). New Engl. J. Med., 224, 722 .

Hadden, W. B (1885). Lancet, 1, 709.

Hadden, W. B. (1885). Lancet, 1, 289.

Jung, R. (1950)

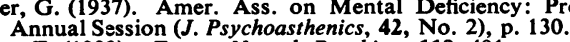

Lotmar, F. (1929). Z. ges. Neurol. Psychiat., 119, 491.

Lucas, W. P. (1927). The Modern Practice of Pediatrics. Macmillan, New York.

Mai, H. and Schaper, G. (1953). Ann. paediat. (Basel), 180, 65.

Nieman, E. A. (1958). M.D. Thesis, University of Liverpool.

Siegert, F. (1910) Ergebn, inn. Med. Kinderheilk, 6, 601.

Schütz and Müller (1953). Quoted (personal communication) in Mai and Schaper (1953)

Topper, A. (1951). Amer. J. Dis. Child., 81, 233

Tredgold, A. F. (1929). Mental Deficiency, Sth ed. Bailliere, Tindall $\&$ Cox, London.

Wagner, R. (1943). Quoted in Topper, A. (1951), loc. cit. 